\title{
The Role of Research Methodology in Enhancing Postgraduate Students Research Experience
}

\author{
Ben K. Daniel \\ University of Otago, Dunedin, New Zealand \\ ben.daniel@otago.ac.nz
}

\begin{abstract}
Postgraduate student research experience is key to understanding the quality of postgraduate education. This article presents the critical factors that can enhance postgraduate students' research experience. The research explored postgraduate students' research experiences $(n=116)$ at a research-intensive public university in New Zealand. The aim was to inform the development of a more personalised and scalable research methodology programme. The study identified several factors that can significantly enhance the postgraduate research experience, including the quality of supervision, institutional and department support, personal investment, and financial support. Also, the study found that courses on research methodology play an essential role in improving the postgraduate experience. In particular, providing research methodology education to students during candidacy enriches postgraduate research experience and contributes to the timely completion of postgraduate education. Despite the demonstrated significance of research methodology in postgraduate education, findings revealed that students are generally dissatisfied with the design and teaching of current courses on research methods. Students said courses on research methods are pedagogically monolithic, conceptual challenging, and inflexibly adaptive to individual future career trajectories. Findings also suggest that the way research methods are taught is disengaged from practical problems, with some teaching focused on the higher level of abstraction, with less opportunity to apply what is gained from research methods courses. This research contributes to the growing need to transform the way we design and teach courses on research methods, and the importance employing a researchled approach to inform the transformation.
\end{abstract}

Keywords: postgraduate research experience, research methodology, postgraduate education, supervisory support, institutional support

\section{Introduction}

Postgraduate students are becoming increasingly diverse, with different interests and goals for pursuing postgraduate education. Diversity is reflected in age, culture, ethnicity, nationality, prior research experience, and financial ability (Abiddin, Ismail and Ismail, 2011). The growing diversity in postgraduate students has created far-reaching challenges for institutions to provide adequate resources and individualised support to complete their studies on schedule and gain enriched research experience to obtain employment or further studies (Daniel, 2018; Spronken-Smith, Cameron and Quigg, 2017). Researchers have explored the notion of postgraduate research experience as a mechanism to understand the quality of postgraduate research programmes and supervision (Grant, Hackney and Edgar, 2014; Muraraneza, Mtshali, and Bvumbwe, 2020; Nachatar Singh, 2018).

Postgraduate research experience describes the student's collections of lived experiences, observations, events, knowledge, and skills acquired during their postgraduate programme. Such an experience is influenced and shaped by many factors, including the quality and nature of available research methodology. As a multidimensional construct, postgraduate research experience consists of students' episodic and perceived experiences during candidacy and the extent to which such experiences contribute to or shape the student's lifelong developmental growth after programme completion. Student completion rates and postgraduate research experience are intertwined phenomena critical to the quality of postgraduate education.

Though various studies have been conducted on factors that contribute to an enhanced postgraduate research experience (see, for example, Noori Hekmat, Rezaei, and Dehnavieh, 2016; Slight, 2017; Trigwell and DunbarGoddet, 2005; Wisker and Kiley, 2014; Wright and Cochrane, 2000), the role of research methodology training has been ignored. Courses on research methodology play a significant role in improving the postgraduate experience. In particular, providing research methodology education to students during candidacy enriches postgraduate research experience and contributes to the timely completion of postgraduate education. Students Research Experience. The Electronic Journal of Business Research Methods, 20(1), pp. 34-48, available online at www.ejbrm.com 
This article reviews factors likely to enhance postgraduate students' research experience and examines the role of research methodology in contributing to the postgraduate research experience. The resarch aimed to develop a more personalised and scalable research methodology programme for postgraduate students.

\section{Related research}

Researching postgraduate student research experience is essential because it enables institutions to better address students' diverse learning needs, provide students with a meaningful pedagogical experience (Jancey and Burns, 2013), and widen future employability horizons. However, most studies in this area have focused on analysing students' understandings about their learning and supervisory experience (Burmeister, 2015; Phillips and Pugh, 2010).

Research has identified several factors that can contribute to an enhanced postgraduate students' research experience, including the nature of institutional support (Humphrey and McCarthey, 1999; Spronken-Smith, Cameron and Quigg, 2017); the quality of postgraduate supervision (Kaur, Kumar and Noman, 2021; Mohamed, Judi and Mohammad, 2017); financial challenges, family commitments, information and services offered to students by institutions (Abiddin, Ismail and Ismail, 2011). The quality of postgraduate student experience and completion rates are correlated (Spronken-Smith, Cameron and Quigg, 2017). However, the issue of postgraduate completion rates is debated elsewhere. For instance, Wright and Cochtane (2000) pointed out disciplinary differences in completion rates. They said that programmes in the Natural Sciences (e.g. Chemistry, Physics, etc.), by their nature, take longer for students to complete their degrees. Lessing and Schultz (2003) added other factors affecting student completion, including student-friendly environment, available administrative procedures and support, understanding scientific and academic requirements, understanding and balancing workload, supervisory support, time management and writing ability.

The quality of supervision remains critical to completion rates and postgraduate research experience. Over the years, several studies have pointed out the importance of postgraduate supervision and institutional support in enriching the postgraduate student experience (Franke and Arvidsson, 2011; Lange and Baillie, 2008; Lee, 2009; Kaur, Kumar and Noman, 2021; Styles and Radloff, 2001). In particular, Lessing and Schulze (2002) saw the research supervisor's task as ensuring that the topic on which a candidate embarks contributes to theory. Research has also reported that a research supervisor's role continually evolves in response to students' experiences (Wisker and Kiley, 2014). Subsequently, the supervisory role is becoming more challenging because most postgraduate students come from various ethnic, cultural, political, economic, linguistic and educational backgrounds. While their attraction and retention are paramount for educational institutions (Alam, Alam and Rasul, 2013), managing diversity dynamics is a significant challenge for institutions. Mohamed, Judi and Mohammad (2017) added that supervisory challenges are attributed to rising expectations in most postgraduate programmes and graduates' quality. There are also supervisory challenges associated with the marked differences between taught and postgraduate research degrees; Masters and Doctoral levels supervision.

Further, the postgraduate is also tasked with ensuring that students understand the research field and the study's context and gain the appropriate research methods needed to solve the identified problem (Daniel, Kumar and Omar, 2018). Factors such as similarity in the student research topic and supervisor's research interest and area of expertise, ability to establish collegial relationships, as well as providing emotional support are the essential determinants of student success in postgraduate education (Fraser and Mathews, 1999; Mouton, 2001; Styles and Radloff, 2000). It has also been pointed out that a positive relationship between a student and supervisor is the key to successful postgraduate programme completion (Peat, Taylor and Franklin, 2005).

A substantial body of research supports the quality of the supervision and institutional factors in contributing to enhancing postgraduate student research experience. However, this research does not acknowledge the role of research methodology in contributing to student success in graduate education. Understanding the relationship between different research methodologies and student experience, especially in a doctoral programme, can add to existing knowledge of enhancing the student research experience (Coronel Llamas and Boza, 2011). 
The overarching purpose of this research was to explore factors likely to contribute to postgraduate students' enhanced research experience. The research also explored the role of research methodology programmes in enhancing students' postgraduate research experience as well as contributing to fulfilling students future research careers. The study also explored students' experiences and challenges of learning research methods courses. The central questions addressed in this research are:

- RQ1. What factors contribute to an enhanced postgraduate research experience?

- RQ2. What is the role of research methodology in influencing the postgraduate student research experience?

\section{Research methods and procedures}

The research was undertaken in a public research-intensive university in New Zealand. The context of the study was situated within an Australasian postgraduate education system, with predominantly research-based degree programmes. In the Australian postgraduate system, methodological research support is predominantly provided by student supervisors, with few exceptions in some programmes where instruction on research methodology is provided to all students regardless of their domain of study. Though there are limited required courses in research methodologies, in the Australasian postgraduate education system, during candidacy, students may often take short courses in skills development relating to research methods or take other programmes such as writing, engaging with the literature, etc.

The present study utilised an embedded mixed methods research design involving an online questionnaire. The questionnaire was adapted from (Trigwell and Dunbar-Goddet, 2005) and consisted of 17 structured questions measured on a 5 Likert scale (1=strongly disagree; 2 =disagree; 3 = neutral; 4 =agree; $5=$ strongly agree), and some open questions. Some items included open-ended questions intended to solicit data to explain participants' reactions and provide contextual insights into the quantitative data. Individual scores on the items in the questionnaire are shown in table 1 . The instrument was tested for reliability, revealing an overall high Cronbach's Alpha ( $\alpha=.936 ; \mathrm{N}=17$ ).

\subsection{Data analysis}

SPSS was used to analyse the quantitative data. Respondents' demographic data were summarised using descriptive statistics (frequency tables and proportions, see Table 2). To extract the key factors that can explain an enhanced postgraduate research experience, exploratory factor analysis was used to describe variability among all observed correlated variables (see Table 1) and isolate those with high correlation measures. Responses to open-ended questions were analysed thematically, and selected quotes were used to provide more in-depth context to the factors extracted from the exploratory factor analysis.

Table 1: Descriptive Statistics

\begin{tabular}{lcc}
\hline Variable & Mean & Std. Deviation \\
\hline My supervisor/s have the skills and subject knowledge to support my research & & 0.9 \\
adequately & 4.2 & 1.2 \\
My supervisor/s make a real effort to understand any difficulties I face & 4.1 & 1.0 \\
My institution values and responds to feedback from research degree students & 3.6 & 0.8 \\
I understand the required standard for the thesis & 4.1 & 0.7 \\
Supervisory support and guidance & 3.6 & 1.6 \\
Supervisory support and guidance & 5.6 & 0.8 \\
There is adequate provision of library facilities & 4.0 & 0.8 \\
I understand the requirements and deadlines for formal monitoring of my progress & 4.3 & 0.8 \\
I understand the requirements of thesis examination & 3.9 & 0.7 \\
I understand my responsibilities as a postgraduate student & 3.4 & 1.5 \\
Access to appropriate facilities such as computer labs, software, and experimental rooms & 5.0 & 1.3 \\
Opportunities to develop a range of research skills & 5.0 & 1.4 \\
Opportunities to develop a range of transferable skills & 5.0 & 1.3 \\
There is appropriate financial support for research activities & 3.2 & 1.1 \\
I am encouraged to think about the range of career opportunities that are available to & & \\
me. & 3.7 & 1.4 \\
Provision of guidance on institutional standards and expectations for your research & & 4.9 \\
degree programme & 4.0 & 0.8 \\
My postgraduate experience so far has improved my analytical skills & \\
There are adequate opportunities available for me to develop my research skills further & 4.0 \\
(e.g. independently carry out research) & 1.0 \\
\hline
\end{tabular}




\begin{tabular}{llc}
\hline Variable & Mean & Std. Deviation \\
\hline My experience so far has helped me to develop a range of communication skills & 4.0 & 0.7 \\
My supervisor/s provide helpful feedback on my progress & 4.2 & 1.0 \\
The research interests in my department or faculty stimulate my work & 3.5 & 1.1 \\
My supervisor/s are available when I need them & 4.2 & 1.0 \\
My department provides a good workshops program for postgraduate students & 3.6 & 1.0 \\
My department provides opportunities for social contact with other research students & 3.1 & 1.1 \\
My department provides opportunities for me to become involved in the broader & 3.1 & 1.1 \\
research culture & & 0.7 \\
Opportunity to develop a range of research skills, e.g. data analysis, performing literature & & 0.8 \\
review & 3.5 & 0.3 \\
Opportunities to develop a range of transferable skills & 3.3 \\
$\begin{array}{l}\text { Provision of guidance on institutional standards and expectations for your research } \\
\text { degree program }\end{array}$ & 4.3 & 0.8 \\
\hline
\end{tabular}

\subsection{Participants characteristics}

One hundred sixteen participants filled in an online questionnaire. Sixty-nine identified as female, and 47(41\%) identified as male. The median age range was between 31-35 years, constituting over a third of the total number of participants, $37(32 \%)$. The degree programmes in which participants were enrolled, were almost equally distributed; 61(53\%) were enrolled in a $\mathrm{PhD}$ programme, and 55(47\%) were enrolled on Masters Degrees. Further, participants were mainly pursuing their degree programmes on campus (or face-to-face), 101(87\%), and 15(13\%) were distance students (see Table 2 with all demographic information).

Table 2: Participants' demographic information

\begin{tabular}{|l|l|}
\hline Variable & Frequency/Percent \\
\hline Age range & \\
\hline$\leq 25$ years & $22(19)$ \\
\hline $26-30$ & $24(21)$ \\
\hline $31-35$ & $37(32)$ \\
\hline $36-40$ & $16(14)$ \\
\hline $41-45$ & $9(8)$ \\
\hline $46-50$ & $4(3)$ \\
\hline $51-55$ & $3(3)$ \\
\hline$\geq 56$ & $1(1)$ \\
\hline & \\
\hline SEX & \\
\hline Female & $69(60)$ \\
\hline Male & $47(41)$ \\
\hline & \\
\hline Programme of study & \\
\hline PhD & $61(53)$ \\
\hline Masters & $55(47)$ \\
\hline & \\
\hline Mode of studies & \\
\hline Primarily a face-to-face learner & $101(87)$ \\
\hline Primarily a distance learner & $15(13)$ \\
\hline & \\
\hline Participant's discipline & \\
\hline Health Sciences and related subjects & $30(26)$ \\
\hline Biological Sciences & $28(24)$ \\
\hline Engineering and Computer Sciences & $23(20)$ \\
\hline Arts and Humanities & $15(13)$ \\
\hline Biomedical and Veterinary Sciences & $11(10)$ \\
\hline Social Sciences & $6(5)$ \\
\hline Physical Sciences & $3(3)$ \\
\hline & \\
\hline & \\
\hline & \\
\hline
\end{tabular}

Though respondents reported diverse research experiences before joining postgraduate education, those with research experience upon completing undergraduate studies were proportional to those who said they gained research experience after completing postgraduate education (see Table 3). 
Table 3: Research experience prior to postgraduate school

\begin{tabular}{ll}
\hline Experience & Frequency/Percent \\
\hline Completed my postgraduate studies & $30(26)$ \\
Completed my undergraduate studies & $29(25)$ \\
Worked in a non-research role & $16(14)$ \\
Worked in the same organisation that I currently work in & $16(14)$ \\
Took a gap year & $10(9)$ \\
Worked as a researcher & $8(7)$ \\
Lecturer & $4(4)$ \\
master student & $1(1)$ \\
work at a private company based on my undergrad qualification & $1(1)$ \\
worked as a professional & $1(1)$ \\
\hline
\end{tabular}

Participants were in various stages of their study programme at the research time. Over two-thirds of the respondents, 71(61\%), were in their second year's study programme, with a median year of 2 years in the programme. More than half, 55(47\%) were writing their theses, and nearly half, 49(42\%), indicated that they were either planning or collecting data for their research projects; $5(4 \%)$ said they submitted their thesis, and $5(4 \%)$ was waiting for viva $4(3 \%)$. There was only one participant who reported expecting to graduate.

\subsection{Factor analysis}

To determine the factors that are likely to influence postgraduate research experience, an exploratory factor analysis (EFA) was performed. Twenty-eight items were extracted using principle-component analysis (PCA) with Varimax (orthogonal) rotation technique. Kaiser-Meyer-Olkin measure of sampling adequacy was determined at a value of .815 , above the recommended value of 0.6. Further, Bartlett's test of sphericity was significant at $\left(\chi^{2}(378)=2257.320 ; p<0.001\right)$. The commonalities were all above 0.4 (see Table 4). Based on these tests, factor analysis was deemed suitable to proceed. From the EFA, seven factors were extracted, which explained $75 \%$ of the variance for the entire set of variables (Table 5 ). The factor loading was considered at $\geq .4$ as a cut-off value to help with better interpretation. Moreover, the statistical power was determined at .80 since the sample $(n=116>100)$ threshold value.

Seven items loaded into the first factor (see table 5). This factor was described as "supervisory support and feedback on student work" , which explained $35.3 \%$ of the variance. The second factor was extracted from 3 items and explained $10.3 \%$ of the variance, and the factor was labelled "institutional support for students to develop research skills". The third factor was extracted from seven items, labelled "personal responsibility and accountability", and explained $8.1 \%$ of the variance. The fourth factor was named "institutional and supervisory support", explaining $7.252 \%$ of the variance. The fifth factor accounted for $5.430 \%$ of the variance and was labelled "departmental research support". The sixth factor explained $4.851 \%$ of the total variance, labelled as "culture of support for research methods skills development". Two items loaded into the seventh factor, referred to as the "financial support". This factor explained $3.912 \%$ of the total variance.

Table 4: Rotated Component Matrix

\begin{tabular}{|c|c|c|c|c|c|c|c|c|}
\hline & \multicolumn{7}{|c|}{ Component } & \multirow[b]{2}{*}{ Commonality } \\
\hline & 1 & 2 & 3 & 4 & 5 & 6 & 7 & \\
\hline $\begin{array}{l}\text { My supervisor/s make a real effort to understand any } \\
\text { difficulties I face }\end{array}$ & .90 & & & & & & & .73 \\
\hline Supervisory support and guidance & .79 & & & & & & & .90 \\
\hline My supervisor/s provide helpful feedback on my progress & .79 & & & & & & & .83 \\
\hline $\begin{array}{l}\text { My supervisor/s have the skills and subject knowledge to } \\
\text { adequately support my research }\end{array}$ & .78 & & & & & & & .77 \\
\hline $\begin{array}{l}\text { My institution values and responds to feedback from } \\
\text { research degree students }\end{array}$ & .65 & & & & & & & .84 \\
\hline My supervisor/s are available when I need them & .63 & & & & .53 & & & .69 \\
\hline Opportunities to develop a range of transferable skills & & .83 & & & & & & .79 \\
\hline Opportunities to develop a range of research skills & & .82 & & & & & & .62 \\
\hline $\begin{array}{l}\text { Provision of guidance on institutional standards and } \\
\text { expectations for your research degree program }\end{array}$ & & .82 & & & & & & .80 \\
\hline $\begin{array}{l}\text { Access to appropriate facilities such as computer labs, } \\
\text { software, and experimental rooms }\end{array}$ & & .77 & & & & & & .83 \\
\hline
\end{tabular}




\begin{tabular}{|c|c|c|c|c|c|c|c|c|}
\hline & \multicolumn{7}{|c|}{ Component } & \multirow[b]{2}{*}{ Commonality } \\
\hline & 1 & 2 & 3 & 4 & 5 & 6 & 7 & \\
\hline $\begin{array}{l}\text { I understand my responsibilities as a postgraduate } \\
\text { student }\end{array}$ & & & .77 & & & & & .83 \\
\hline I understand the required standard for the thesis & & & .76 & & & & & .85 \\
\hline I understand the requirements of thesis examination & & & .69 & & & .43 & & .73 \\
\hline $\begin{array}{l}\text { There are adequate opportunities available for me to } \\
\text { further develop my research skills ( e.g. independently } \\
\text { carry out research) }\end{array}$ & .45 & & .61 & & & & & .84 \\
\hline $\begin{array}{l}\text { I am encouraged to think about the range of career } \\
\text { opportunities that are available to me. }\end{array}$ & & & .48 & & .42 & & & .72 \\
\hline There is adequate provision of library facilities & & & .41 & & & & & .79 \\
\hline $\begin{array}{l}\text { I understand the requirements and deadlines for formal } \\
\text { monitoring of my progress }\end{array}$ & & & .401 & & & & & .75 \\
\hline $\begin{array}{l}\text { Opportunity to develop a range of research skills, e.g. } \\
\text { data analysis, performing literature review }\end{array}$ & & & & .88 & & & & .86 \\
\hline Opportunities to develop a range of transferable skills & & & & .85 & & & & .83 \\
\hline $\begin{array}{l}\text { Provision of guidance on institutional standards and } \\
\text { expectations for your research degree program }\end{array}$ & & & & .80 & & & & .85 \\
\hline Supervisory support and guidance & & & & .80 & & & & .72 \\
\hline $\begin{array}{l}\text { My department provides opportunities for social contact } \\
\text { with other research students }\end{array}$ & & & & & .76 & & & .83 \\
\hline $\begin{array}{l}\text { My department provides opportunities for me to become } \\
\text { involved in the broader research culture }\end{array}$ & & & & & .76 & & & .63 \\
\hline $\begin{array}{l}\text { My department provides a good workshops program for } \\
\text { postgraduate students }\end{array}$ & & & & & .72 & & & .75 \\
\hline $\begin{array}{l}\text { My postgraduate experience so far has improved my } \\
\text { analytical skills }\end{array}$ & & & & & & .85 & & .61 \\
\hline $\begin{array}{l}\text { My experience so far has helped me to develop a range of } \\
\text { communication skills }\end{array}$ & & & & & & .66 & & .72 \\
\hline $\begin{array}{l}\text { There is appropriate financial support for research } \\
\text { activities }\end{array}$ & & & & & & & .78 & .80 \\
\hline $\begin{array}{l}\text { The research interests in my department or faculty } \\
\text { stimulate my work }\end{array}$ & & & & & & .45 & .64 & .77 \\
\hline
\end{tabular}

\section{Result}

Postgraduate research experience is a critical phenomenon in postgraduate education. This study identified a wide range of factors likely to enhance the postgraduate student research experience (the relative influence of these factors is presented in Table 5, Table 6 and Figure 1).

Table 5: Total Variance Explained

\begin{tabular}{|c|c|c|c|c|c|c|c|c|c|}
\hline \multirow[t]{2}{*}{ Component } & \multicolumn{3}{|c|}{ Initial Eigenvalues } & \multicolumn{3}{|c|}{$\begin{array}{l}\text { Extraction Sums of Squared } \\
\text { Loadings }\end{array}$} & \multicolumn{3}{|c|}{$\begin{array}{l}\text { Rotation Sums of Squared } \\
\text { Loadings }\end{array}$} \\
\hline & Total & $\begin{array}{l}\% \text { of } \\
\text { Variance }\end{array}$ & Cum \% & Total & $\begin{array}{l}\% \text { of } \\
\text { Variance }\end{array}$ & Cum \% & Total & $\begin{array}{l}\% \text { of } \\
\text { Variance }\end{array}$ & Cum $\%$ \\
\hline 1 & 9.874 & 35.265 & 35.265 & 9.874 & 35.265 & 35.265 & 4.678 & 16.706 & 16.706 \\
\hline 2 & 2.869 & 10.245 & 45.510 & 2.869 & 10.245 & 45.510 & 3.480 & 12.429 & 29.135 \\
\hline 3 & 2.271 & 8.110 & 53.621 & 2.271 & 8.110 & 53.621 & 3.150 & 11.249 & 40.383 \\
\hline 4 & 2.031 & 7.252 & 60.873 & 2.031 & 7.252 & 60.873 & 3.054 & 10.908 & 51.291 \\
\hline 5 & 1.520 & 5.430 & 66.303 & 1.520 & 5.430 & 66.303 & 2.936 & 10.487 & 61.778 \\
\hline 6 & 1.358 & 4.851 & 71.153 & 1.358 & 4.851 & 71.153 & 2.032 & 7.255 & 69.033 \\
\hline 7 & 1.095 & 3.912 & 75.066 & 1.095 & 3.912 & 75.066 & 1.689 & 6.033 & 75.066 \\
\hline 8 & .945 & 3.376 & 78.441 & & & & & & \\
\hline 9 & .751 & 2.684 & 81.125 & & & & & & \\
\hline 10 & .667 & 2.383 & 83.509 & & & & & & \\
\hline 11 & .606 & 2.166 & 85.674 & & & & & & \\
\hline 12 & .518 & 1.850 & 87.524 & & & & & & \\
\hline 13 & .490 & 1.751 & 89.275 & & & & & & \\
\hline 14 & .439 & 1.568 & 90.844 & & & & & & \\
\hline 15 & .406 & 1.450 & 92.294 & & & & & & \\
\hline
\end{tabular}




\begin{tabular}{|c|c|c|c|c|c|c|c|c|c|}
\hline \multirow[t]{2}{*}{ Component } & \multicolumn{3}{|c|}{ Initial Eigenvalues } & \multicolumn{3}{|c|}{$\begin{array}{l}\text { Extraction Sums of Squared } \\
\text { Loadings }\end{array}$} & \multicolumn{3}{|c|}{$\begin{array}{l}\text { Rotation Sums of Squared } \\
\text { Loadings }\end{array}$} \\
\hline & Total & $\begin{array}{l}\text { \% of } \\
\text { Variance }\end{array}$ & Cum $\%$ & Total & $\begin{array}{l}\% \text { of } \\
\text { Variance }\end{array}$ & Cum \% & Total & $\begin{array}{l}\% \text { of } \\
\text { Variance }\end{array}$ & Cum \% \\
\hline 16 & .335 & 1.198 & 93.492 & & & & & & \\
\hline 17 & .275 & .983 & 94.475 & & & & & & \\
\hline 18 & .253 & .903 & 95.377 & & & & & & \\
\hline 19 & .215 & .769 & 96.146 & & & & & & \\
\hline 20 & .188 & .672 & 96.818 & & & & & & \\
\hline 21 & .177 & .632 & 97.450 & & & & & & \\
\hline 22 & .153 & .547 & 97.997 & & & & & & \\
\hline 23 & .144 & .514 & 98.510 & & & & & & \\
\hline 24 & .122 & .436 & 98.946 & & & & & & \\
\hline 25 & .102 & .363 & 99.309 & & & & & & \\
\hline 26 & .073 & .261 & 99.571 & & & & & & \\
\hline 27 & .066 & .236 & 99.807 & & & & & & \\
\hline 28 & .054 & .193 & 100.000 & & & & & & \\
\hline
\end{tabular}

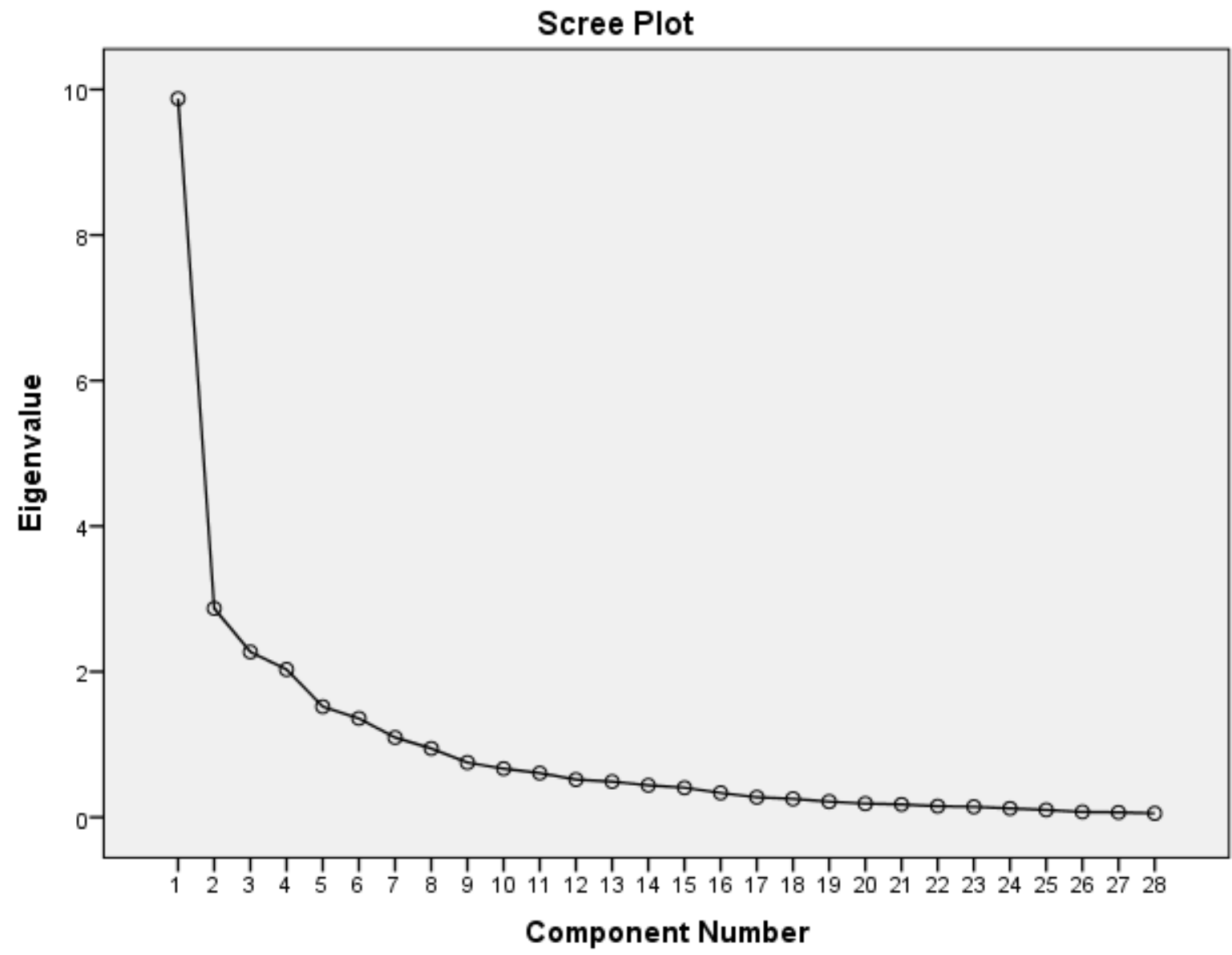

Figure 1: Scree Plot with extracted factors

The factors identified are the quality of supervisory support, institutional and departmental guidance and support, personal accountability and motivation, the culture of support for research methods, and financial assistance availability.

The supervisory factor involves providing guidance and support, timely feedback on the student work, and supervisors' availability when needed. Students expect an ideal supervisor to make every effort to understand the issues students face during their candidacy. They also anticipated supervisors to be knowledgeable in the respective research area and reasonably know research methodologies. 
Institutional policies and expectations guide supervisors' interaction with students. In addition to the supervisory support, results in this study suggest that students expect their institutions to provide a learning environment where they can acquire a range of transferable domain and research skills. They stated that institutions need to provide appropriate research facilities and clear guidance on the research program's expectations and achievable standards.

Respondents said departmental support is also essential, especially, making social contact opportunities with other research students and academic staff. It was also clear that students appreciate the opportunity to research a research laboratory setting among shared research interests.

The study also found that being accountable and personal responsibility is critical ingredients of enhanced postgraduate research experience. Respondents said that students need to take advantage of the availability of the range of resources in their institutions and adhere to deadlines. Training on research methodology is another central element in enriching students' postgraduate experience. The data suggests that when students are offered opportunities to develop a range of research skills (e.g. data analysis, performing literature review) and acquire communication skills, they can widen their employability opportunities. Table 6 shows the degree of association between various critical factors the sense of an enhanced postgraduate research experience.

Table 6: Correlation of factors likely to influence enhanced research experience

\begin{tabular}{|l|l|l|l|l|l|l|}
\hline & SS & IS & RMS & DS & FS & PA \\
\hline SS & & & & & & \\
\hline IS & $.741^{* *}$ & & & & & \\
\hline RMS & $.513^{* *}$ & $.585^{* *}$ & & & & \\
\hline DS & $.610^{* *}$ & $.793^{* *}$ & $.744^{* *}$ & & & \\
\hline FS & $.428^{* *}$ & $.450^{* *}$ & $.435^{* *}$ & $.550^{* *}$ & & \\
\hline PA & $.608^{* *}$ & $.693^{* *}$ & $.607^{* *}$ & $.609^{* *}$ & $.472^{* *}$ & \\
\hline
\end{tabular}

**Correlation is significant at the $\mathbf{0 . 0 1}$ level (2-tailed).

Supervisory guidance (SS); institutional support (IS); research methodology support (RMS); department support (DS); financial support (FS); personal accountability (PA).

\subsection{The supervisory factor}

Supervisors are essential knowledge conduits between postgraduate students and the subject of their research and they can contribute to a fulfilled postgraduate research experience. Results in this study showed that having a knowledgeable and supportive supervisor remains an integral part of an enhanced postgraduate research experience as one respondent mentioned; "Supervisory support is the most important part of postgraduate education, guidance and individual support are probably the most important things a supervisor can offer to their students." The quality of supervision also determined a student's satisfactory completion of the degree. Respondents stated that supervisors are movers and inspirers in times when students are facing obstacles; "if the student has a good and active supervisor, he will be able to complete the research on time."

Respondents view research supervisors as a source of knowledge. It is vital to individuals who continually encourage students throughout the learning process, provide feedback, and mentor them during their programme's writing period. "Supervisors are key through the writing process and providing timely feedback to ensure the quality of work." "Having the guidance of supervisors is paramount. While I do understand that doing a thesis is supposedly an independent act - having the 'expert' guidance of your supervisor in providing feedback is essential for me."

However, supervising postgraduate students remains a complex form of teaching, requiring the supervisor to navigate a complicated relationship between student, institution, and department. According to the survey data, when conflicting expectations between the student and supervisor are not adequately stated and communicated in advance, challenges may prevail in the teaching environment, leading to dissatisfaction with the postgraduate program if not timely resolved. Respondents noted that being transparent about expectations and maintaining open communication in the supervisory process can help students to plan their academic programme and seek other sources of support when necessary; "transparent and timely communication; advanced notice of supervisory absences to allow the student to plan around their schedule; improved career development support." 
Many postgraduate students who responded to the survey view supervisors as inspiring students, providing direction and general guidance during the research process, leading them to success and opportunities for better future career prospects. Fundamental to this expectation is that being supervised is a developmental process involving nurturing relationships between supervisors and students.

\subsection{The department support factor}

While the supervisory relationship is essential, the broader intellectual climate in a department helps students feel a sense of belonging to the department rather than isolated. Respondents said that a welcoming and supportive intellectual environment could enhance their research experience.

Respondents said a nurturing department climate needs to include facilitating social contact with other research students and staff. They also pointed out the need to provide a safe environment that cultivates and broadens the research culture. "Opportunities to get to work on other research projects with other academics from the dept., so that I can learn how other academics conduct their research opportunities for teaching."

Though lacking in many departments, some respondents stated that departments should offer formal training in research methods to enable students to gain the knowledge necessary to undertake their research and become career researchers. "Departments should offer courses on research methods better to prepare their students for a fulfilled research career."

The results of this study suggest that the research methods expertise of the student's supervisor also plays a role not only in setting the direction for student research but also contributes to the successful and timely completion of the postgraduate degree; "acquiring the appropriate science in what you are doing is important. However, still, your adviser (or supervisory support) needs to guide you on how to appropriately use your knowledge in the process of doing your thesis".

\subsection{Supervisors as teachers of research methodology}

Many institutions consider supervision mainly as one aspect of teaching. Students are assigned to supervisors as a logical extension of existing teaching in a particular area purely based on their research interests, regardless of whether they are formally trained in the subject content. Students expect supervisors to have the skills and knowledge in the subject area and methods and procedures for undertaking research. The lack of a clear rationale for assigning students creates anxiety among supervisors. Early career supervisors, in particular, are concerned about their ability to successfully supervise a student to completion because students' success or failure reflects on the supervisor's competence and future reputation. Such concerns are equally shared among experienced supervisors, who are only knowledgeable in the single methodological area (Daniel, 2018).

Being knowledgeable in varied research methodologies is essential for enhancing postgraduate research experience. Respondents in the survey expected supervisors to be well versed in many research methodologies and avail that knowledge when needed. Some respondents stated that they learned research methods and techniques through their supervisors; "one of my supervisors was a biostatistician, and she took it upon herself to make sure I was up to speed"; others said they took formal instruction or methodological support programmes (e.g. workshops). Regardless, a significant number of students view supervisors as an additional means of learning research methods. "I was also introduced to the various study 'types', as well as many of the biases and other factors one should look for when evaluating existing research".

\subsection{The institutional and department support factor}

Many institutions provide clear policies guiding the development and execution of postgraduate programmes; however, some are unaware of their learning environment's diverse growing students' expectations. Students expected institutions to work together with supervisors to provide adequate support for students, provide appropriate research training, and develop transferable research skills and knowledge vital to a career as a researcher.

Respondents said they expected institutions to offer students the opportunity to develop a range of research skills (e.g. data analysis, performing literature review) and an environment to create a range of transferable skills. They also expected that the institution and supervisors guide institutional standards and expectations for the quality of research. Further, students expect institutions to provide a conducive postgraduate student 
research environment and an adequate infrastructure to support postgraduate study. "I would like more institutional support and to have a lot more support from my supervisors, but that is not going to happen...."

Students said they feel confident when they are provided with adequate supervisory and institutional support, as one participant remarked: "I think that both institutional support and supervisory support play a major role in the development of confidence in me."

Respondents also said they expect institutions to set standards and procedures for students and supervisors to interact during studies. Some said institutions need to be aware of personal circumstances, as any decision made by the majority may affect individual student completion of their programme. "Research committees want to add more works, and they do not consider student capacity, money and time." In situations where postgraduate students experience significant tension between student and institutional expectations, tension can impede on-time completion. The institutions may face a research funding shortfall (McCormack, 2004).

\subsection{The personal accountability factor}

Respondents said that while other factors play a critical role in determining enhanced postgraduate research experience, taking personal responsibility for setting the direction and duration of one's research programme is paramount to completing the program.

Some stated that taking personal responsibilities around planning and managing time helped them navigate the postgraduate program's complex trajectories. "To complete my dissertation, it was.... necessary to ensure I managed my time well, particularly as I am a mother with two sons, aged 14 and 16, and was studying at a distance."

Working independently is an essential quality for success in postgraduate education. To work independently, postgraduate students are expected to develop confidence, take personal initiative and accountability in their program, become self-regulated learners, and participate in setting the directions for their programme and exercise control over their learning. "While the other factors are important, ultimately, I have to complete the work myself, and I have a reasonably strong belief that I can teach myself the basics of most concepts if needed."

Respondents reported that confidence and ability to identify growth areas are important determinants of success in the postgraduate program and ultimately gain an enhanced postgraduate research experience; "developing confidence and awareness of one's areas of weakness and strengths are important elements contributing to gaining important research experience." Others stated that balancing postgraduate studies and family life is critical. "My work, study and family balance will be the most crucial component to completing a thesis."

\subsection{The research methodology factor}

Research methodology plays a vital role in postgraduate education and future career opportunities. Respondents share a recognition that research methodology is a critical factor in fostering enriched postgraduate research experience. They stated that research methods courses enable students to undertake their research projects successfully. "Formally ensuring students are equipped with the necessary to complete project autonomously, "Others stated that knowledge and skills in research methods help students to carry out better research projects, "I think learning about research methodology can improve knowledge and skills in that field, just like any other subject such as math or writing'.

In other areas of clinical research, respondents view knowledge of research methodology as key in fostering critical thinking skills in students interact with domain content: "research methods in nursing research has helped me to critique articles in other subjects. "Also enables one to distinguish good research projects in the future."

There was a shared belief among participants that the provisions of courses on methodology contribute to the timely completion of the postgraduate program; "depending on the content or the course, and the relevance to research subject, a research methods course may help a student submit a thesis on time". "Receiving training in the necessary research methods is paramount to completing your research project in the allocated time. I feel like this is an area to which the institution should special attention should be paid." 
Respondents who received some form of training in research methods courses reported that research methodology improved the quality of their thesis and helped them gain a better grade: "for me, understanding research methodology helped me gain the best grade I could for my dissertation..." They also reported that courses on research methodology also helped them to transition from theory to practice: "helpful foundation for thesis, and also helpful when translating research into clinical practice." Others stress that methods courses also prepare them to become better researchers, improve their writing skills in other subjects, and produce a high-quality thesis.

Courses on research methods improve research literacy and provide students with the possibility of gaining essential theoretical and methodical skills to help them understand domain-specific knowledge and to be able to consume research produced in their respective areas effectively. They also mentioned that research knowledge helps them engage in knowledge translation and prepare them to become critical consumers of scholarly articles and thoroughly understand the knowledge to underpin research outcomes.

Some students emphasised that teaching research methods in non-course postgraduate programs is necessary to develop the skills needed to read and understand their subject domain. Others perceive methodology to produce new knowledge, advance science, and contribute to a future research career. "I believe that further training in research methodology would be greatly beneficial for my future research endeavours....."

\subsection{Challenges in learning research methodology}

Though the value of taking formal courses in research methods in postgraduate education is evident, many participants in this study reported significant challenges in learning research methodology. They said that learning methodology related to research design, data collection and analysis, writing, and concepts in quantitative research methods; "I struggle to make sense with numbers, more specifically trying to understand what these numbers are telling me. I want to learn and know how to read those numbers."

Students reported difficulties understanding theory and how to use it in their research projects. More specifically, many said the problem in effectively engaging with the literature, citing complexity in organising credible and critical literature reports and choosing an appropriate theoretical framework to guide their research; "Getting myself to organise my research and to build up my theoretical framework" and "understanding the complicated jargon in the literature of research methods was a problem for me", as well as "I am not sure whether I had chosen the right theory and how to relate it to my study."

A growing interest in the use of mixed methods for researching students was identified in the data. However, many institutions are not offering formal training in mixed methods, and students said this is a problem in using mixed methods in their research. Some of the challenges mentioned in using mixed methods included challenges of research design and integrating various data into one study.

"It is impossible to learn everything about research in one or two semesters or a year! Lack of adequate time for learning research methodology was also identified as an additional challenge. Many institutions teach research methodology in a single semester, and however, students find it hard to absorb the content of research methodology in a single semester.

\subsection{The financial factor}

Availability of financial support in student assistantship, scholarships and awards was regarded as essential. Those who were self-funded and worked alongside their program faced significant challenges. "It is hard trying to concentrate on your thesis when you are tired from working enough hours to pay your rent, let alone for food. Money is more than just rent and food, and it is peace of mind and time.

Respondents stated that funding is necessary during data collection, "I need funding to ensure I have the resources for data collection and to assist in transcribing information gained verbatim", and others stated, ".... writing a thesis and working is stressful.

Surprising, not all respondents view funding as an essential factor in enhancing the postgraduate experience, "although key in research, funding plays a secondary role in writing a meaningful research thesis", though many acknowledged that it is essential to have the scholarship to complete the postgraduate program on time. Others reported that students are more likely to complete their program on time if institutions are firm about 
the expiration of scholarships. "There is a strong incentive for me to finish on time (3 years) because my current scholarship funding will cease after that (my scholarship is payable for a maximum of 3 years of full-time study)." It is not uncommon for students to continue with their program even after their scholarships run out. One respondent stated that even when their scholarship ran out, they were still motivated to complete their program, "this is important, but it is possible without it. My scholarship ran out last year, and I am still managing to continue, so I do not believe funding is quite so as important as the support received from the people in my life."

\section{Discussion}

There is a substantive body of literature on the importance of postgraduate student's research experience in contributing to increased completion rates, fulfilled research career and access to employment opportunities (see, for example, Drennan, 2008; Hodsdon and Buckley, 2011; Ginns et al., 2009; Lopatto, 2004). Postgraduate research experience describes student learning experience, the quality of supervision provided to them and the forms of support and resources available for them to access during their candidacy.

This research identified vital factors that contribute to enhanced postgraduate education: the quality of supervision, institutional and departmental support, personal responsibility and accountability, and financial support availability. The importance of the supervisory factor revealed in this research is consistent with previous research that suggests that postgraduate students who closely work with their supervisors gain a better research experience than those who left to work independently (Lyons, Scroggins and Rule, 1990; Yeoh and Doan, 2012).

The literature has shown that the quality of supervision and other institutional factors significantly improve postgraduate students' experience, ultimately leading to high student submission and completion rates (see, for example, Spronken-Smith, Cameron and Quigg, 2017; Wisker et al., 2003; Wisker, 2012). In the institution where this research was conducted, postgraduate supervisors are expected to meet with students for a minimum of an hour per week, and there is an ongoing debate on whether or not supervision is considered teaching or research. However, supervisors often come under increasing pressure to achieve minimum teaching hours, and they might not have time to provide adequate support needed for students to succeed in their postgraduate education. In some instances, where supervision is considered research, time dedicated to it might not be recognised. Another challenge is that supervisors might be assigned students or be obligated to take on students working on areas where they might not have expertise or interest, creating tension in the supervisor-student relationship. Furthermore, some supervisors might not be familiar with the research methods students might need to use.

In addition to institutional support, institutional transparency in policy dissemination can enhance the postgraduate experience and leads to timely programme completion. This finding also substantiates the view that possible tension exists between institutions' conceptions of research represented in policies and plans and individual postgraduate research students' understanding (McCormack, 2004); hence, precise communication and clarity on policy are essential to the success of postgraduate studies education.

Although the various body of previous research supports factors for enhancing postgraduate research experience identified in the present research (see Hodsdon and Buckley, 2011; Trigwell and Dunbar-Goddet, 2005), the role of research methodology in enhancing the postgraduate research experience and other factors pointed out in the literature. The current study revealed that courses on research methods play a significant role in enhancing the postgraduate student research experience. In particular, respondents collectively reported that access to courses on research methodology during their candidacy had enriched their postgraduate research experience and time contributed to the timely completion of postgraduate education. Further, results suggest that providing students with training on research methodology can significantly enhance postgraduate research experience, and such experience can live on beyond the period of candidature.

Students need to acquire knowledge in research methodology to cover many research processes, including research design, data collection and analysis, writing, and presentation. Therefore, providing postgraduate students with courses on research methods is essential since the postgraduate education model is predominately research-driven. Some students entering postgraduate programmes mighty not have prior research methods training necessary for undertaking research, especially at a doctoral level. Students lack 
research training, and some thesis supervisory expertise in research methodology is critical, and formal training in methods is equally important.

Providing postgraduate students with courses on research methods is essential since the postgraduate education model is predominately research-driven. Consistent with recent research (see for example, (Daniel, 2018; Daniel, Kumar and Omar, 2018), results revealed that postgraduate students face significant challenges in learning research methods, yet there is relatively limited research into how research methods courses are designed and taught (Kilburn, Nind and Wiles, 2014). In the light of the challenges students face in learning research methodology, postgraduate supervisors need to demonstrate the ability to timely help students acquire required knowledge in various research methods and data analytical approaches during students' candidacy. Some students entering postgraduate programmes mighty not have prior research methods training necessary for undertaking research, especially at a doctoral level. Some postgraduate students' lack research training, thesis supervisory expertise in research methodology is critical, and formal training in methods is equally important.

\section{Limitation and conclusion}

Postgraduate student research experience is key to understanding the quality of postgraduate research programmes. Postgraduate student research experience describes student learning experience, supervision, resources, the research community, progress and assessment, access to vital research support resources and professional development during their candidacy. The study identified several factors that can significantly enhance a postgraduate research experience, including the quality of supervision, institutional and department support, personal investment, and financial support. The study found that courses on research methodology play a significant role in improving the postgraduate experience. In particular, providing research methodology education to students during candidacy enriches postgraduate research experience and contributes to the timely completion of postgraduate education.

This research contributes to the growing need to develop a substantial and sustainable pedagogical research culture in research methodology. The research presented in the article has some limitations. First, the data presented are based on the students' perceptions, and they may be limited to the respondents' experiences, shaped by the postgraduate program, where they were enrolled or completed during the survey. In addition, the survey carried out in the research presented in the current article was only limited to students and did not include supervisors' views regarding challenges they face supervising students and how they mentor students in research methods.

Though results presented in the article suggest that specific factors seem to have high loading, regression models would have been ideal for isolating definitive predictors of enhanced postgraduate research experience and associated factors such as completion rates employability. However, multicollinearity issues were identified, making it difficult to assess the effect of independent factors. Future work, therefore, needs to focus on further analysis of interactions of these factors (table 8) and possibly employment of alternative statistical approaches (e.g. causal models).

Finally, besides supporting the various factors contributing to student enhanced postgraduate experience, institutions need to consider offering discipline-specific methodological skills to equip students with the necessary training to gain broader employability and different research career trajectories.

Teaching research methodology requires imparting a combination of theoretical understanding, procedural knowledge, and skills competence. It requires individuals to develop in framing, designing, collecting and analysing data, presenting, interpreting, and communicating results. Further, the design and delivery of research methodology programs need to be organised in such a way to support students to become aware of the complexity of the subject and to learn how to become professional researchers (Coronel Llamas and Boza, 2011).

Students stated that learning research methodology during candidacy can significantly contribute to their timely completion and lead to many research opportunities and career trajectories. However, respondents reported dissatisfaction with the way current courses on research methods are taught. Students find courses on research methods pedagogically monolithic, conceptual challenging, and inflexible to individual future 
career trajectories. Furthermore, students find the pedagogical modalities of many research methods courses disengaged from practical problems yet unattainable at a conceptual level.

This article contributes to the growing importance of researching the postgraduate research experience phenomenon, and it adds the role of research methodology in preparing students for research careers within and outside of academia. The article explores how higher education institutions can actively create positive and cohesive research cultures by teaching research methods for postgraduate researchers.

\section{References}

Abiddin, N. Z., Ismail, A. and Ismail, A., 2011. The effective supervisory approach in enhancing postgraduate research studies. International Journal of Humanities and Social Science, 1(2), pp.206-217.

Alam, F., Alam, Q. and Rasul, M. G., 2013. A pilot study on postgraduate supervision. Procedia Engineering, (56), pp.875881.

Burmeister, O., 2015. Improving professional IT doctorate completion rates. Australasian Journal of Information Systems, 19, pp.55-70. https://doi.org/10.3127/ajis.v19i0.1073

Coronel Llamas, J. M. and Boza, Á., 2011. Teaching research methods for doctoral students in education: Learning to enquire in the university. International Journal of Social Research Methodology, 14(1), pp.77-90.

Daniel, B. K. and Harland, T. 2018. Higher education research methodology: A step-by-step guide to the research process. London: Routledge.

Daniel, B.K., 2018. Contestable professional academic identity of those who teach research methodology. International Journal of Research \& Method in Education, 41(5), pp.548-561.

Daniel, B., Kumar, V. and Omar, N. 2018. Postgraduate conception of research methodology: Implications for learning and teaching. International Journal of Research \& Method in Education, 41(2), pp. 220-236.

Drennan, J. 2008. Postgraduate Research Experience Questionnaire: reliability and factor structure with Masters in Nursing graduates. Journal of Advanced Nursing, 62(4), pp.487-498.

Franke, A. and Arvidsson, B., 2011. Research supervisors' different ways of experiencing supervision of doctoral students. Studies in Higher Education, 36(1), pp.7-19.

Fraser, R. and Mathews, A., 1999. An evaluation of the desirable characteristics of a supervisor. Australian Universities Review, (42), pp.5-7

Ginns, P., Marsh, H. W., Behnia, M., Cheng, J. H. and Scalas, L. F., 2009. Using postgraduate students' evaluations of research experience to benchmark departments and faculties: Issues and challenges. British Journal of Educational Psychology, 79(3), pp.577-598.

Grant, K., Hackney, R., and Edgar, D., 2014. Postgraduate research supervision: An'agreed'conceptual view of good practice through derived metaphors. International Journal of Doctoral Studies, 9, pp. 43-60. DOI:10.28945/1952

Hodsdon, L. and Buckley, A., 2011. Postgraduate research experience survey 2011 results-York: The Higher Education Academy. Available at: https://www.heacademy.ac.uk/system/files/PRES_report_2011_0.pdf [Accessed 26 October 2021]

Humphrey, R. and McCarthy, P., 1999. Recognising difference: providing for postgraduate students. Studies in Higher Education, 24(3), pp.371-386.

Jancey, J. and Burns, S., 2013. Institutional factors and the postgraduate student experience. Quality Assurance in Education, 21(3), pp.311-322.

Kaur, A., Kumar, V. and Noman, M., 2021. Partnering with doctoral students in research supervision: opportunities and challenges. Higher Education Research \& Development, 1-15. DOI:10.1080/07294360.2020.1871326

Kilburn, D., Nind, M. and Wiles, R. 2014. Learning as researchers and teachers: The development of a pedagogical culture for social science research methods? British Journal of Educational Studies, 62(2), pp. 191-207.

Lange, K. and Baillie, C., 2008. Exploring graduate student learning in applied science and student-supervisor relationships: views of supervisors and their students. Engineering education, 3(1), 30-43.

Lee, N. J. 2009. Professional doctorate supervision: exploring student and supervisor experiences. Nurse Education Today, 29(6), pp.641-648.

Lessing, A. C. and Schulze, S. 2002. Postgraduate supervision and academic support: students' perceptions. South African Journal of Higher Education, 16(2), 1pp.39-149.

Lessing, A. and Schulz, S. 2003. Postgraduate supervision: students' and supervisors' perceptions. Acta Academica, 35(3), pp.161-184.

Lopatto, D. 2004. Survey of undergraduate research experiences (SURE): First findings. Cell biology education, 3(4), pp. 270277.

Lyons, W., Scroggins, D. and Rule, P. B. 1990. The mentor in graduate education. Studies in Higher Education, 15(3), pp.277285.

McCormack, C., 2004. Tensions between student and institutional conceptions of postgraduate research. Studies in Higher Education, 29(3), pp.319-334.

Mohamed, H., Judi, H. M., and Mohammad, R., 2017, April. Postgraduate students experience in research supervision. In AIP Conference Proceedings, (1830)1, p. 050003). AIP Publishing. 
Mouton, J. 2001. How to succeed in your Master's and Doctoral studies. A South African guide and resource book. Pretoria: Van Schaik.

Muraraneza, C., Mtshali, N., and Bvumbwe, T., 2020. Challenges in postgraduate research supervision in nursing education: Integrative review. Nurse Education Today, 89, 104376. DOI: 10.1016/j.nedt.2020.104376

Nachatar Singh, J. K., 2018. What are the factors that contribute to postgraduate international students' academic success? A Malaysian qualitative study. Higher Education Research \& Development, 37(5), 1035-1049. doi:10.1080/07294360.2020.1871326

Noori Hekmat, S., Rezaei, M. and Dehnavieh, R., 2016. Effective factors on postgraduate students research experience in Kerman University of Medical Sciences. Research in Medical Education, 8(3), 34-44.

Peat, M., Taylor, C.E. and Franklin, S. 2005. Re-engineering of undergraduate science curricula to emphasise the development of lifelong learning skills. Innovations in Education and Teaching International, 42 (2), pp.135-146.

Phillips, E. and Pugh, D. 2010. How to get a PhD: A handbook for students and their supervisors. Berkshire: McGraw-Hill Education (UK).

Slight, C., 2017. Postgraduate research experience survey 2017. Higher Education Academy. Available at: https://www. advancehe. ac. uk/knowledge-hub/postgraduate-research-experience-survey-report-2017. [Accessed 30 October 2021]

Spronken-Smith, R., Cameron, C. and Quigg, R., 2017. Factors contributing to high PhD completion rates: a case study in a research-intensive university in New Zealand. Assessment \& Evaluation in Higher Education, pp.1-16.

Styles, I., and Radloff, A., 2000. Affective reflections: Postgraduate students' feelings about their theses. Quality in postgraduate research: Making ends meet, pp.203-214.

Styles, I., and Radloff, A., 2001. The synergistic thesis: Student and supervisor perspectives. Journal of Further and Higher Education, 25(1), pp.97-106.

Trigwell, K. and Dunbar-Goddet, H., 2005. The research experience of postgraduate research students at the University of Oxford. Institute for the Advancement of University Learning. Available at: https://citeseerx.ist.psu.edu/viewdoc/download?doi=10.1.1.472.4279\&rep=rep1\&type=pdf [Accessed 12 December 2021]

Wisker, G. and Kiley, M., 2014. Professional learning: lessons for supervision from doctoral examining. International Journal for Academic Development, 19(2), pp.125-138.

Wisker, G., 2012. The good supervisor: Supervising postgraduate and undergraduate research for doctoral theses and dissertations. New York: Palgrave Macmillan.

Wisker, G., Robinson, G., Trafford, V., Warnes, M. and Creighton, E., 2003. From supervisory dialogues to successful PhDs: Strategies supporting and enabling the learning conversations of staff and students at postgraduate level. Teaching in Higher Education, 8(3), pp.383-397.

Wright, T. and Cochrane, R., 2000. Factors influencing successful submission of PhD theses. Studies in Higher Education, 25(2), pp.181-195.

Yeoh, J. S. W. and Doan, T., 2012. International research students' perceptions of quality supervision. International Journal of Innovative Interdisciplinary Research, (3), pp. 10-18. 